\title{
Family resilience - definition of construct and preliminary results of the Polish adaptation of the Family Resilience Assessment Scale (FRAS)
}

\author{
Natalia Nadrowska $a^{A, B, C, D, E, F}$, Magdalena Błażek ${ }^{A, B, C, D, E, F}$, Aleksandra Lewandowska-Walter ${ }^{A, C, D, E, F}$ \\ Institute of Psychology, University of Gdansk, Gdansk, Poland
}

BACKGROUND

The article describes construct of family resilience with the main focus on the model Walsh. The aim of this article is to present preliminary results: adaptation, reliability, statistical analyses of the Family Resilience Assessment Scale (FRAS) for the Polish population.

\section{PARTICIPANTS AND PROCEDURE}

Participants $(n=329)$, aged $18-35$, completed experimental Polish version of the FRAS (SPR - Skala Prężności Rodzin$n e j)$. In the procedure of adaptation, scale was translated and modified into Polish. Scale consists of the following subscales: Family Communication and Problem Solving, Utilizing Social and Economic Resources, Maintaining a Positive Outlook, Family Connectedness, Family Spirituality and Ability to Make Meaning of Adversity.

\section{RESULTS}

The reliability of the experimental Polish version of the FRAS for the entire scale and five subscales are satisfac- tory. Only subscale Ability to Make Meaning of Adversity obtained reliability of less than 0.7 . Taking into account the diversity of gender and declaring the passage through the difficult events were observed significant differences in the three scales: Family Communication and Problem Solving, Family Connectedness, Ability to Make Meaning of Adversity and total scale of FRAS.

\section{CONCLUSIONS}

The work on the questionnaire is still in progress and the results presented here should be considered as preliminary. In the next steps, the number of men should be increased in order to perform confirmatory factor analysis. Future studies should take into account a number of factors and contexts (e.g. family structure, social and cultural context and the type of stressful event).

\section{KEY WORDS}

adaptation; reliability; family resilience

CORRESPONDING AUthor - Natalia Nadrowska, Institute of Psychology, University of Gdansk, 4 Bażyńskiego St., 80-952 Gdansk, Poland, e-mail: nadrowskanatalia@gmail.com

AUthors' Contribution - A: Study design - B: Data collection - C: Statistical analysis - D: Data interpretation .

E: Manuscript preparation · F: Literature search $\cdot$ G: Funds collection

To Cite this ARTICLE - Nadrowska, N., Błażek, M., \& Lewandowska-Walter, A. (2017). Family resilience - definition

of construct and preliminary results of the Polish adaptation of the Family Resilience Assessment Scale (FRAS).

Current Issues in Personality Psychology, 5(4), 313-322.

RECEIVED 02.02.2017 · REVIEWED 17.03.2017 • ACCEPTED 25.03.2017 • PUBLISHED 22.05.2017 


\section{BACKGROUND}

\section{DEFINITION OF FAMILY RESILIENCE}

In the literature family resilience is described in various ways, primarily as a property of families, a process of adaptation or a process of growth responses to crisis. Family resilience refers to the characteristics and capabilities of the family, so that the family is able to survive difficult times and adapt to challenging conditions (McCubbin \& McCubbin, 1988). This is a unique response to stress exhibited by the family. This response depends on the risk factors and protective factors, level of development, context and a common perspective (Hawley \& DeHaan, 1996). These are the processes that allow family adaptation and coping, support the survival of a difficult time, a return to pre-crisis functioning and development as a result of experiencing difficulties (Walsh, 1996). The concept of family resilience is widely described by McCubbin, Thompson and McCubbin (1996), Van Breda (2001) and Walsh (2006) and in Polish literature is presented by Lachowska $(2012 ; 2014)$ and Gąsior (2012; 2014).

\section{DEVELOPMENT OF THE CONCEPT OF FAMILY RESILIENCE}

The family resilience concept was derived from research on family stress and strengths. Research on stress began to appear in the 1930s and covered: the period of the Great Depression, the effects of World War II, reaction to alcoholism, delinquency, illness, disaster, imprisonment, drug abuse, and rape. Research on family strengths emerged in the 1970 s, and various researchers distinguished the following strengths of the family: autonomy, coherence, cohesion, affective responsiveness, communication, flexibility and adaptability, spirituality and values, family identity, family rituals, boundaries and hierarchies, social support, and problem solving (Nichols, 2013; Van Breda, 2001). At that time, some models on which the development of family resilience was based were created. The last of them was the Resiliency Model of Family Adjustment and Adaptation by McCubbin and McCubbin. The models have been widely described in the literature (see: Nichols, 2013; Van Breda, 2001).

\section{WALSH APPROACH TO FAMILY RESILIENCE}

Walsh (2006; 2013) after many years of clinical work presented a contemporary approach to family resilience. According to her concept, the construct of family resilience contains relational, ecological and developmental perspectives. She drew attention to the varied family structure, emphasized family life course, cultural diversity, changing gender roles and socioeconomic disparity.

Walsh $(2006$; 2013) created a conceptual model, which included three over-arching constructs: belief systems, organizational patterns, and communication and problem solving. These three over-arching constructs relate to the family functioning. Each of the main constructs contains three sub-constructs.

Belief systems are created in the society and transmitted from generation to generation, through rituals and various activities (Sixbey, 2005). A belief system affects the perception and response to family crisis situations. Effective functioning, growth and problem solving are strengthened by a belief system shared by family members (Walsh, 2012). The belief systems enable making meaning of adversity, a positive outlook and transcendence and spirituality. The first sub-construct is focused on making meaning of adversity, which helps families understand, accept and deal with stressful situations. Thanks to making meaning of adversity, family members gain new insight into the crisis situation. They increase their perspective and perceive their difficulties as understandable in the context of the negative situation. The perception of the crisis and prolonged adverse conditions as a common challenge strengthens family bonds and family resilience. The crisis is perceived as meaningful, comprehensible, manageable (Walsh, 2012). The second sub-construct includes maintaining a positive outlook. This sub-construct refers to sense of hope, holds an optimistic bias, confidence in coping with adversity and builds on potential. Family members take an active initiative to resolve the difficulties and accept the case which they failed to solve (Walsh, 2012). The third sub-construct contained in the system of beliefs is transcendence and spirituality. Transcendent beliefs relate to the broader goals and values. Within this process the following are taken into account: participation in religious or spiritual practices, connection with nature, inspirations and inventions (innovative solutions and new capability), creative expression (music, writing) or transformation (redefining life priorities). This process allows learning, change and growth from adversity (Walsh, 2010; 2013).

The second set of processes involves family organization. The family, in order to meet the demands, must organize itself in different ways (Walsh, 2003; 2012). The organization of the family plays a special role at a time when the family encounters adverse conditions. Organizational patterns of the family can be drawn from past and current relationships, as well as cultural norms and values and expectations (Walsh, 2006). The organizational patterns of the family consist of the following processes: flexibility, connectedness, social and economic resources (Walsh, 2012). Flexibility relates to adaptive changes. In order for the family to function properly, the family needs a flexible structure that enables it to reorganize through modifications in the family system and provides sta- 
bility by routine and rituals when facing adversity or transformations. It is important that this process has a strong leadership that provides guiding, nurturing, and protection of children and family members. Flexibility assumes different family structures including: single-parent family, two-parent household, stepfamilies, and extended family (Walsh, 2006). Connectedness refers to mutual support, commitment and collaboration of family members with each other and mutual respect for individual differences or needs, autonomy, and boundaries (Walsh, 2012). Family members engage in common activities that are important to them as a family unit, even though they are not always consistent with their own interests. Family connectedness depends on the phase of the family life cycle, family hierarchy, and emotional and physical intimacy of family members with each other. It is important to maintain regular contact between family members who are not in physical proximity and the desire to reconnect and repair the disturbed relationship (Walsh, 2006). Social and economic resources depend on kin, social and community networks. Family members care about the financial security of the family, and seek to maintain a balance between the strains of work and family. If necessary, the family is able to seek institutional support (Walsh, 2012). Walsh (2013) draws attention to the community-based training and practice applications, which show the usefulness of the family resilience approach in adverse situations.

The third and final over-arching construct of family resilience highlighted by Walsh (2013) is communication and problem solving. According to Becvar (2013) factors such as effective communication, problem-solving and coping with stress contribute to protecting families from the impact of risk factors. In this over-arching process the family resilience is facilitated by the following three processes: clarity, open emotional expression and collaborative problem-solving (Walsh, 2013). The clarity process refers to transmission of clear and consistent information. Family members looking for and speaking real information seek to verify ambiguous messages (Walsh, 2012). It is essential that there is common recognition by the family that the problem exists and a shared understanding of the circumstances of painful losses. The family should be open to conversation and questions, and seek to allay doubts. (Walsh, 2006). Open emotional expression during unfavorable circumstances and crisis situations or prolonged stress allows family members to share a wide range of feelings. Each person reacts to difficult events in a different way. Some family members with difficult emotions deal more quickly than others who need more time to recover (Walsh, 2006). Necessary to this process is mutual empathy, and tolerance for different responses to situations by others family members (Walsh, 2012). Of relevance to family resilience are also moments of sharing positive feelings, lifting spirits, spending pleasant times together, finding time to rest and respite from problems (Walsh, 2006). The process of collaborative problem solving includes the generation of ideas (creative brainstorming), drawing attention to the resourcefulness of family members. It also covers collaborative decision making, conflict management and negotiation. The family takes action to meet its own goals. Family members draw conclusions from past failures, trying to prevent occurrence of problems and preparing for possible problems (Walsh, 2012).

\section{FAMILY RESILIENCE ASSESSMENT SCALE}

Construct of family resilience has been measured using multiple scales, including the following: The Family Hardiness Index (FHI), the Family Time and Routine Index (FTRI), the Family Traditions Scale (FTS), the Family Coping Index (FAMCI), and the Family Coping Coherence Index (FCCI) (see: McCubbin, Thompson, \& McCubbin, 1996). These scales measured the various aspects of family resilience, but not the whole construct. Measurement of family resilience required the use of several scales, whereas the Family Resilience Assessment Scale (FRAS) covers most aspects of family resilience and presents a complete construct.

Sixbey (2005), based on a model created by Walsh, developed a tool to assess family resilience - the Family Resilience Assessment Scale (FRAS), which provides six subscales: Family Communication and Problem Solving (FCPS, $\alpha=.96$ ), Utilizing Social and Economic Resources (USER, $\alpha=.85$ ), Maintaining a Positive Outlook (MPO, $\alpha=.86$ ), Family Connectedness (FC, $\alpha=.86$ ), Family Spirituality (FS, $\alpha=.70$ ) and Ability to Make Meaning of Adversity (AMMA, $\alpha=.88$ ). Cronbach's $\alpha$ coefficient for the total scale was .96.

Adaptation of the FRAS has been carried out in Romania (Bostan, 2014), Turkey (Kaya \& Arici, 2012), Malta (Dimech, 2014) and China (Li, Zhao, Zhang, Lou, \& Cao, 2016). The factor analysis in Romania identified six factors. Cronbach's $\alpha$ coefficients for dimensions of the Romanian version were: .90 for Family Communication and Problem Solving, .76 for Utilizing Social and Economic Resources, .59 for a Positive Outlook, .02 for Family Connectedness, .72 for Family Spirituality, and .63 for Ability to Make Meaning of Adversity. Similarly, in Malta a six-factor solution was found, labeled the Malta version of the FRAS (FRAS-MV). The reliability of the FRAS-MV scale was as follows: Family Communication and Problem Solving $(\alpha=.87)$, Maintaining a Positive Outlook $(\alpha=.79)$, Outreach $(\alpha=.70)$, Ability to Make Meaning of Adversity ( $\alpha=.68)$, Community and Friendship Outlook $(\alpha=.68)$, Family Connectedness $(\alpha=.22)$, and for the entire scale $\alpha=.86$. Adaptation of the FRAS in Turkey revealed a four-factor solution, composed of the following scales: Family Communication and Problem Solving, Utilizing 
Social and Economic Resources, Maintaining a Positive Outlook, Ability to Make Meaning of Adversity. Cronbach's $\alpha$ coefficient for the total scale of the Turkish version of the FRAS was .92. The adaptation of the Turkish version of the FRAS consists of 42 items. The Chinese version of the FRAS consists of 32 items, with 3 subscales: Family Communication and Problem Solving $(\alpha=.94)$, Utilizing Social Resources $(\alpha=.50)$, Maintaining a Positive Outlook $(\alpha=.80)$. Cronbach's $\alpha$ for the Chinese version of the FRAS for the total scale was .95. Conducted adaptations revealed a difference in the factor structure. In Malta, Turkey and China as well as in the United States the $\alpha$ coefficient for the entire scale of the FRAS was higher than .90. Both in Romania and Malta a six factorial solution was accepted. In Turkey a four factorial solution was adopted and in China a three factor solution was accepted. Therefore, family resilience can be considered as a culturally dependent construct.

Research of the FRAS has included families with a child diagnosed with an autism spectrum disorder (see: Plumb, 2011; Cripe, 2013; Teixeira, 2015; Simelane, 2015), in the area of youth suicide (see: Seo \& Jung, 2013), among vocational rehabilitation clients (see: Openshaw, 2011), in the area of parentadolescent communication (see: Suk-Ja \& Hee-Jeong, 2013) and in the area of art therapy (see: Rahimian, Zadech, Mohammadi, \& Pakdaman, 2015).

\section{AIMS OF THE STUDY}

The goal of this research was the adaptation of FRAS into Polish population and exploration of internal consistency reliability of the total scale and subscales. With the presentation of preliminary results from the use of FRAS, report helps to enable the study of family resilience in the Polish population.

\section{PARTICIPANTS AND PROCEDURE}

\section{PARTICIPANTS}

The adaptation of the FRAS questionnaire was carried out using two samples and the participants were in the period of early adulthood (Brzezińska, 2013). The target group consisted of 329 people, university students and people lived in the Tricity (a metropolitan area in Poland in Pomerania, consisting of three cities: Gdansk, Sopot and Gdynia). $83 \%$ of the respondents were women. Their mean age ranged from 18 to $35(M=22.50$, $S D=4.01) .72 \%$ of the respondents had a secondary education, $15 \%$ had a master's degree, and the remaining $13 \%$ were people with an undergraduate education. $79 \%$ of respondents came from families with two parents, and the remaining $21 \%$ of the respondents come from families in which a single parent raised a child
(9.4\%), where the parents were divorced but both were involved in child care $(7.9 \%)$, a blended family (3\%) or an adoptive family $(0.3 \%)$. $53.8 \%$ of respondents were in a relationship, and $46.8 \%$ declared not to be in a relationship. $35.6 \%$ of participants lived with their parents, while $64.4 \%$ lived outside the family home. Among people living outside the family home $54.2 \%$ lived without a partner, and $45.8 \%$ lived with a partner. The respondents answered the question of whether the life cycle of their family had experienced any of the following difficulties: financial problems, serious health problems, bereavement, breakup, or crisis situations. In $78.4 \%$ of participants difficult situations had occurred, and in $21.6 \%$ such events had not occurred.

\section{MEASURE}

Sixbey (2005) on the basis of Walsh's model created a questionnaire measuring family resilience - the Family Resilience Assessment Scale (FRAS). The FRAS consists of six subscales, with a total of 54 items and a Likert scale (1 - strongly disagree to 4 - strongly agree), including 4 reverse scored items. She proposed the following subscale: Family Communication and Problem Solving (FCPS, $\alpha=.96$, with 27 items, e.g. Our family structure is flexible to deal with the unexpected and We feel good giving time and energy to our family), Utilizing Social and Economic Resources (USER, $\alpha=.85$, with 8 items, e.g. We can depend upon people in this community and We receive gifts and favors from neighbors), Maintaining a Positive Outlook (MPO, $\alpha=.86$, with 6 items, e.g. We feel we are strong in facing big problems), Family Connectedness (FC, $\alpha=.70$, with 6 items, e.g. We think we should not get too involved with people in this community), Family Spirituality (FS, $\alpha=.88$, with 4 items, e.g. We seek advice from religious advisors), Ability to Make Meaning of Adversity (AMMA, $\alpha=.96$, with 3 items, e.g. The things we do for each other make us feel a part of the family). The total reliability Cronbach's $\alpha$ was .96, and has good concurrent criterion validity with three well-known scales - .91 for Family Assessment Device 1 (FAD 1) (Epstein, Baldwin, \& Bishop; 1983), .85 for Family Assessment Device 2 (FAD 2) (Epstein, Baldwin, \& Bishop, 1983), .85 for Personal Meaning Index (PMI) (Reker, 2005). Results of the full scale of the FRAS range from 54 to 216 points. The higher the score, the higher the family resilience.

\section{PROCEDURE}

Translation of the FRAS questionnaire into Polish was based on the consent of Sixbey (2005). Primarily, there were three translators: two psychologists who speak fluent English and a psychologist/English philologist. Then the group of family psychology experts determined a unified version of the questionnaire 
items. A preliminary version of the questionnaire was carried out as a pilot study in a group of 26 people, psychology students (84.6\% women, $M=24.92, S D=$ 2.42). The pilot study allowed for correction of items that respondents assessed as unclear. Again, items content was evaluated by a group of competent judges/psychologists and led to the study of the second sample of participants. The respondents participating in the research filled in an experimental version of the Polish adaptation of Sixbey's Family Resilience Assessment Scale (SPR - Skala Prężności Rodzinnej) made by Nadrowska, Błażek and Lewandowska-Walter. Cronbach's $\alpha$ was used to analyze the internal consistency reliability of the total scale and subscales.

\section{RESULTS}

\section{RELIABILITY OF POLISH VERSION OF FRAS}

The $\alpha$ coefficients for all subscales of FRAS were as follows: 94 for Family Communication and Problem Solving (FCPS), .79 for Utilizing Social and Economic Resources (USER), .81 for Maintaining a Positive Outlook (MPO), .76 for Family Connectedness (FC), .86 for Family Spirituality (FS) and .60 for Ability to Make Meaning of Adversity (AMMA). The total scale reliability coefficient of $\alpha=.95 . \alpha$ reliability values were satisfactory for five scales. Only in the case of one scale was the $\alpha$ coefficient lower than $.70(\alpha=$ .60 for Ability to Make Meaning of Adversity). Cronbach's $\alpha$ values for the Polish version of the FRAS are presented in Table 1.

\section{DIFFERENCES BETWEEN WOMEN AND MEN IN RESULTS OF FRAS IN POLISH CULTURE}

The next step was to analyze whether gender differentiated the FRAS total scale or subscales. Due to the unequal number of respondents in groups, calculations were carried out using Mann-Whitney test. Table 2 shows the results concerning the differences between women $(n=273)$ and men $(n=56)$. In the areas of Family Communication and Problem Solving (FCPS), Family Connectedness (FC), Ability to Make Meaning of Adversity (AMMA) and total scale of FRAS uncovered differences between females and males. A tendency was observed for the subscales of Utilizing Social and Economic Resources (USER) and Family Spirituality (FS). In the one subscale - Maintaining a Positive Outlook (MPO) - no significant differences were found.

\section{DIFFERENCES BETWEEN PEOPLE LIVING IN A RELATIONSHIP AND SINGLE PEOPLE IN THE RESULTS OF SUBSCALES AND TOTAL SCALE OF FRAS}

Further analyses were carried out in order to assess whether family resilience was perceived differently by participants living in a relationship $(n=177)$ or living singly $(n=152)$. A tendency was observed for the subscales of Family Communication and Problem Solving $($ FCPS $)(p<.100, t(329)=1.72)$ and Ability to Make Meaning of Adversity (AMMA) $(p<.100, t(329)$ $=1.77$ ). In other scales of the FRAS and the full scale no statistically significant results were observed.

\section{DIFFERENCES BETWEEN INDIVIDUALS \\ LIVING IN A RELATIONSHIP AND SINGLY \\ IN THE RESULTS OF SUBSCALES \\ AND TOTAL SCALE OF FRAS}

Subsequent analysis was performed to determine the differences between women living in a relationship ( $n=158)$ and single women $(n=115)$ in the results of subscales and the total scale of the FRAS. No significant effects were found in any of the subscales of the FRAS or the full scale between analyzed groups of women. Results of differences between men living in a relationship $(n=19)$ and single men $(n=37)$ turned

Table 1

$\alpha$ reliability of scales included in the Polish version of the FRAS

Cronbach's $\alpha$

Polish version of the FRAS

\begin{tabular}{lc}
\hline Family Communication and Problem Solving (FCPS) & .94 \\
Utilizing Social and Economic Resources (USER) & .79 \\
Maintaining a Positive Outlook (MPO) & .81 \\
Family Connectedness (FC) & .76 \\
Family Spirituality (FS) & .86 \\
Ability to Make Meaning of Adversity (AMMA) & .60 \\
Total scale & .95 \\
\hline
\end{tabular}


Table 2

Differences between women and men in the results of subscales and total scale of the FRAS

\begin{tabular}{|c|c|c|c|c|c|}
\hline & \multicolumn{2}{|c|}{ Mdn } & \multirow[t]{2}{*}{$U$} & \multirow[t]{2}{*}{$p$} & \multirow[t]{2}{*}{$r$} \\
\hline & $\begin{array}{l}\text { Females } \\
(n=273)\end{array}$ & $\begin{array}{l}\text { Males } \\
(n=56)\end{array}$ & & & \\
\hline $\begin{array}{l}\text { Family Communication and Problem Solving } \\
\text { (FCPS) }\end{array}$ & 77.11 & 75.61 & 6277.50 & $.035^{*}$ & .12 \\
\hline $\begin{array}{l}\text { Utilizing Social and Economic Resources } \\
\text { (USER) }\end{array}$ & 19.38 & 19.38 & 6463.00 & $.068^{\mathrm{a}}$ & .10 \\
\hline Maintaining a Positive Outlook (MPO) & 15.50 & 15.50 & 7266.50 & .556 & .03 \\
\hline Family Connectedness (FC) & 16.50 & 15.50 & 5708.50 & $.003^{* *}$ & .16 \\
\hline Family Spirituality (FS) & 9.25 & 7.50 & 6436.00 & $.062^{\mathrm{a}}$ & .10 \\
\hline $\begin{array}{l}\text { Ability to Make Meaning of Adversity } \\
\text { (AMMA) }\end{array}$ & 7.00 & 7.00 & 5610.00 & $.001^{* * *}$ & .18 \\
\hline Total scale of FRAS & 158.00 & 152.00 & 5884.50 & $.007^{* *}$ & .15 \\
\hline
\end{tabular}

Note. Mann-Whitney $U$ test; $r$ - effect size statistic.

${ }^{\mathrm{a}} p<.100 ;{ }^{*} p<.050 ;{ }^{* *} p<.010 ;{ }^{* * *} p \leq .001$.

Table 3

Differences between women and men who reported experiencing difficult events in the results of subscale and total scale of the FRAS

\begin{tabular}{|c|c|c|c|c|c|}
\hline & \multicolumn{2}{|c|}{ Mdn } & \multirow[t]{2}{*}{$U$} & \multirow[t]{2}{*}{$p$} & \multirow[t]{2}{*}{$r$} \\
\hline & $\begin{array}{l}\text { Females } \\
(n=218)\end{array}$ & $\begin{array}{l}\text { Males } \\
(n=40)\end{array}$ & & & \\
\hline $\begin{array}{l}\text { Family Communication and Problem Solving } \\
\text { (FCPS) }\end{array}$ & 77.15 & 75.11 & 3674.00 & .110 & .10 \\
\hline $\begin{array}{l}\text { Utilizing Social and Economic Resources } \\
\text { (USER) }\end{array}$ & 19.38 & 19.38 & 3845.00 & .234 & .07 \\
\hline Maintaining a Positive Outlook (MPO) & 15.50 & 15.50 & 4320.00 & .926 & .01 \\
\hline Family Connectedness (FC) & 16.50 & 15.50 & 3041.50 & $.002^{* *}$ & .19 \\
\hline Family Spirituality (FS) & 9.50 & 6.50 & 3653.00 & .102 & .10 \\
\hline $\begin{array}{l}\text { Ability to Make Meaning of Adversity } \\
\text { (AMMA) }\end{array}$ & 7.17 & 7.00 & 3279.50 & $.011^{*}$ & .16 \\
\hline Total scale of FRAS & 158.50 & 152.00 & 3456.00 & $.037^{*}$ & .13 \\
\hline
\end{tabular}

Note. Mann-Whitney $U$ test; $r$ - effect size statistic.

${ }^{*} p<.050 ;{ }^{* *} p<.010 ;{ }^{* * *} p \leq .001$.

out to be statistically insignificant. Similar results were observed in the group of women discussed above.

\section{DIFFERENCES BETWEEN INDIVIDUALS WHO \\ HAVE EXPERIENCED DIFFICULT EVENTS AND WHO HAVE NOT EXPERIENCED THEM IN RESULTS OF SUBSCALES AND FULL SCALE OF FRAS}

Due to the unequal number of respondents in groups, calculations were conducted using the Mann-Whitney test. Another group of statistical analyses was performed to determine the differences between those who have experienced $(n=258)$ and those who have not experienced $(n=71)$ in the cycle of family life difficult or crisis events. No significant effects were observed in any of the subscales of the FRAS or the full scale between people have experienced difficult events and people who have not experienced them. Analysis of the differences between women who have experienced difficult events $(n=218)$ and women who have not experienced them $(n=55)$ did not reveal statistically significant results. In no subscales of the FRAS or full scale were significant effects found between men who have experienced difficult events 
( $n=40)$ and men who have not experienced them $(n=16)$. The next step was to analyze differences between women $(n=218)$ and men $(n=40)$ who have experienced difficult events in the results of subscales and the full scale of the FRAS. In the areas of Family Connectedness (FC), Ability to Make Meaning of Adversity (AMMA) and the total scale of FRAS differences were found between women and men. Women obtained higher median scores on those scales than men. The results are presented in Table 3.

\section{DISCUSSION}

Preliminary adaptation of the Family Resilience Assessment Scale and examining its psychometric properties in Polish culture were the aims of the present study. The next purpose was to present the primary results of the level of family resilience in Polish culture, using an experimental version of the Polish adaptation of the FRAS.

Translation of the FRAS into Polish was based on the recommendations of Sixbey (2005). A pilot study was performed to correct items of the questionnaire. Then a unified final experimental Polish version of the FRAS was established.

The FRAS was developed to conduct research on family resilience in the United States population, and the results may differ from those in the Polish population. The $\alpha$ reliability value for the total original scale of the FRAS was .96, and for the Polish version of the FRAS was .95. Cronbach's $\alpha$ values for the subscales of the American version of the Family Resilience Assessment Scale (FRAS) were between .74 and .96. The values for the subscales of the Polish version of the FRAS were lower than in the United States, but for five scales they were satisfactory (.76 to .94). Only the scale Ability to Make Meaning of Adversity obtained an $\alpha$ coefficient of .60. The highest $\alpha$ reliability for the Polish version was for Family Connectedness (.76), which was higher than the United States (.70), and the lowest reliabilities were for the five following scales: Family Communication and Problem Solving (FCPS), Utilizing Social and Economic Resources (USER), Maintaining a Positive Outlook (MPO), Family Spirituality (FS) and Ability to Make Meaning of Adversity (AMMA) (.60 to .94). In Poland, Malta, Turkey and China as well as in the United States the $\alpha$ coefficient for the entire scale of the FRAS was higher than .90. In the Romanian, Maltese and experimental Polish version of the FRAS as in the original version of the questionnaire a six factorial solution was accepted. In Turkey, a four factorial solution was accepted, in China a three-factor solution. In Poland, work on the adaptation of the questionnaire is still ongoing; in this article preliminary results are presented.

The differences between the cultures may explain the results of the reliability scale. Researchers have shown that coping with stress vary depending on the cultural context (Chun, Moos, \& Cronkite, 2006). According to Walsh (2006), the family resilience depends on the socio-cultural context. Variables associated with ethnicity should be taken into account to explain the level of family resilience (McCubbin \& McCubbin, 2013). Culture is the broader context of family life and imposes some rules and principles that set the framework for the functioning of the family (Bronfenbrenner, 1979; Carter \& McGoldrick, 1989). In different cultures, different values dominate, and in Poland, love and family happiness are considered timeless values (Ruszkiewicz, 2013).

The second purpose was to present the primary results of the level of family resilience in Polish culture, using an experimental version of the Polish adaptation of the FRAS. The differences in the level of family resilience between females and males were also examined. Women scored a higher median value than men on the following scales: Family Communication and Problem Solving (FCPS), Family Connectedness (FC) and Family Spirituality (FS). Women also achieved higher scores than men in the overall results of the scale. The same values were obtained by men and women on two scales: Utilizing Social and Economic Resources (USER) and Ability to Make Meaning of Adversity (AMMA). No statistically significant results were obtained in regard to one subscale - Maintaining a Positive Outlook (MPO).

These results indicate that women in the areas of communication, problem solving, connectedness and spirituality are able to use their resources better than men. This may show that females in a crisis situation with regard to these areas demonstrate higher resilience than males.

In comparison to the studies of Sixbey (2005), women were found to obtain higher score results on the Utilizing Social and Economic Resources (USER) and Family Connectedness (FC) scales than men. Research of family resilience refers to the examination of the functioning of the family as a unit rather than to the study of differences between men and women. The study of family resilience is carried out in families that have experienced difficulties and crisis situations. Studies have concerned families with autistic children (Bayat, 2007; Cripe, 2013; Plumb, 2011; Simelane, 2015; Teixeira, 2015), stepfamilies (Coleman, Ganong, \& Russell, 2013), families that have experienced losses (Boss, 2013; Greeff \& Human, 2013), and families with children with severe disabilities (Hartshorne, Schafer, Stratton, \& Nacarto, 2013). In assessing the level of family resilience the seriousness of the difficult events faced by the family should be taken into account (Walsh, 2006; 2013).

The next aim was concerned with the differences between people who live in a relationship and single people in the area of subscales and the total score of the FRAS. The results showed only a tendency 
in two scales: Family Communication and Problem Solving (FCPS) and Ability to Make Meaning of Adversity (AMMA). Analysis of the differences between women who are in a relationship and single women did not show significant differences. Similar results were observed between the groups of men who are in relationships and single men. This means that people living in a relationship and single people probably exhibit the same level of family resilience and a similar level of mobilization of their resources in a crisis situation. Walsh $(2006 ; 2013)$ suggested that the assessment of family resilience also depends on the structure of the family and not only one model of family resilience exists. Lavee, Olson and McCubbin (1987) investigated the effect of stressful life events and transitions on family functioning and well-being. Fernandez, Schwartz, Chun and Dickson (2013) reviewed the literature and research in the field of family resilience and parenthood and found that the resources which allow the family to survive difficult situations were: the ability to create new solutions, social skills, family cohesion and the autonomy of family members. Family resilience was studied in area of individual characteristics in relation to single parent families and factors such as emotional expression, perseverance, and self-confidence were identified (Greeff \& Ritman, 2005). According to Greeff and Human (2013), the impact of individual factors (e.g., age, gender) and family factors (e.g., family structure, developmental level, financial security) on the level of family resilience in the field of research on parental death was also identified.

In the analysis to provide the answer to the next question, it was verified whether the level of family resilience is connected with experienced adverse events. No difference was found in the level of family resilience in terms of the total scores of the FRAS and the subscales between those who have experienced difficulties in their lives and those who have not experienced them. Analysis of the differences between men who reported having experienced difficult events and men who have not experienced them did not show significant differences in the results of subscales or the total scale of the FRAS. Similar results were obtained in the group of women. However, when taking into account the gender differences and reporting having experienced difficult events, significant differences were observed in the following aspects: Family Connectedness (FC) Ability to Make Meaning of Adversity (AMMA) and the total scale of the FRAS. Walsh (2006) pointed out that the assessment of family resilience should take into account the cycle of family life, both past and present, as events and ways of coping with difficulties. Family resilience is a construct that refers to emergency situations, adverse circumstances, and prolonged stress, which allows the family to survive, cope, and grow after a crisis (Walsh, 2002; 2006). DeHaan, Hawley, Deal (2013) studied the resilience of a family at three time points - before the crisis, during the crisis and after the crisis - which allowed examination of individual paths of family resilience. Family resilience is a construct that refers to a crisis or difficult situations, normative transitions (Walsh, 2006; 2016) and the stressors of everyday life (Patterson, 2002). In this study, the results of people who have not experienced adverse situation should be considered with caution, because we included in the study only serious and critical events, without taking into account the stressors of daily life and normative crises related to the individual development of family members and family life cycle.

\section{CONCLUSIONS}

Work on the Polish questionnaire of the FRAS is still in progress. The presented results should be considered preliminary. In studies on the experimental Polish version of the scale a six-factor structure was used. In the next steps of the adaptation there will be an increased number of men and confirmatory factor analysis will be performed. So far, in the group of 329 people aged 18 to 35 , only $17 \%$ were men.

As indicated in the literature and research, family resilience is an individual response of the family to a specific stressor, and many factors should be considered and taken into account. It is important to observe the resilience both now and in the long term, and take into account its particular stressors, protective factors and risks (DeHaan, Hawley, \& Deal, 2013). Assessment of the family resilience should include a family history of the struggle, the type of stressor, the response to a stressor, varied family structures, and the social, economic and cultural context (Walsh, 2003; 2006; 2013).

The research presented in the article is focused on the comparison of the level of family resilience between men and women, between people who are in a relationship and single, and between those whose families have experienced difficult events and people who have not experienced such events. The results of the present research should be considered with caution. Family resilience is a construct that refers to the family as a unit and, as mentioned, evaluating the level of family resilience should take into account a variety of contexts. The collected results require further analysis taking into account the multifaceted construct which in fact family resilience is. Future studies should include: education level of respondents, family structure, social and cultural context and the type of stressful events. Also the distinction between normative transformations, daily stressors, predictable and unpredictable stressful events and the seriousness of the crisis should be taken into account. 


\section{References}

Bayat, M. (2007). Evidence of resilience in families of children with autism. Journal of Intellectual Disability Research, 51, 702-714. doi: 10.1111/j.1365-2788. 2007.00960.x

Becvar, D. S. (2013). Facilitating family resilience in clinical practice. In D. S. Becvar (ed.), Handbook of family resilience (pp. 51-64). New York: Springer Science + Business Media. doi: 10.1007/978-1-46143917-2_4

Boss, P. (2013). Resilience as tolerance for ambiguity. In D. S. Becvar (ed.), Handbook of family resilience (pp. 285-297). New York: Springer Science + Business Media. doi: 10.1007/978-1-4614-3917-2_17

Bostan, C. M. (2014). Translation, adaptation and validation on Romanian population of FRAS instrument for family resilience concept. Communication, Context, Interdisciplinarity, 3, 351-359. Retrieved from http://upm.ro/cci/?pag=CCl-03/vol03-Eco

Bronfenbrenner, U. (1979). The Ecology of Human Development. Cambridge, Mass: Harvard University Press.

Brzezińska, A. I. (ed.). (2013). Psychologiczne portrety człowieka. Praktyczna psychologia rozwojowa [Psychological portraits of human. Practical developmental psychology]. Sopot: Gdańskie Wydawnictwo Psychologiczne.

Carter, B., McGoldrick, M. (1989). Overview: The Changing Family Life Cycle - A Framework for Family Therapy. In B. Carter \& M. McGoldrick (eds.), The Changing Family Life Cycle. Boston-London-Sydney-Tokyo: Allyn and Bacon, 3-28.

Chun, C. A., Moos, R. H., \& Cronkite, R. C. (2006). Culture: A fundamental context for the stress and coping paradigm. In P. T. P. Wong \& L. C. J. Wong (eds.), Handbook of multicultural perspectives on stress and coping (pp. 29-53). New York: Springer.

Coleman, M., Ganong, L., \& Russell, L. T. (2013). Resilience in stepfamilies. In D. S. Becvar (ed.) Handbook of family resilience (pp. 85-103). New York: Springer Science + Business Media. doi: 10.1007/ 978-1-4614-3917-2_6

Cripe, C. T. (2013). Family resilience, parental resilience and stress mediation in families with autistic children [Dissertation]. Retrieved from http:// pqdtopen.proquest.com/doc/1462534031.html? $\mathrm{FMT}=\mathrm{ABS}$

DeHaan, L. G., Hawley, D. R., \& Deal, J. E. (2013). Operationalizing family resilience as process: Proposed methodological strategies. In D. S. Becvar (ed.), Handbook of family resilience (pp. 17-29). New York: Springer Science + Business Media. doi: 10.1007/978-1-4614-3917-2 2

Dimech, S. (2014). Validating the Family Resilience Assessment Scale to Maltese families [Master's thesis Abstract ]. University of Malta. Abstract retrieved from https://www.um.edu.mt/library/oar/handle/ $123456789 / 4331$
Epstein, N. B., Baldwin, L. M., \& Bishop, D. S. (1983). The McMaster Family Assessment Device. Journal of Marital and Family Therapy, 9, 171-180. doi: 10.1111/j.1752-0606.1983.tb01497.x

Fernandez, I.T., Schwartz, J. P., Chun, H., \& Dickson, G. (2013). Family resilience and parenting. In D. S. Becvar (ed.), Handbook of family resilience (pp. 119136). New York: Springer Science + Business Media. doi: 10.1007/978-1-4614-3917-2_8

Gąsior, K. (2012). Funkcjonowanie noo-psychospoteczne i problemy psychiczne dorostych dzieci alkoholików [The functioning of the noo-psychosocial and mental health problems of adult children of alcoholics]. Warsaw: Difin.

Gąsior, K. (2014). Prężność rodzinna - nowe wyzwanie dla profilaktyki [Family resilience - new challenge for the prevention]. Resocjalizacja Polska [Polish Journal of Social Rehabilitation], 6, 79-88.

Greeff, A. P. \& Human, B. (2013). Family resilience relative to parental death. In D. S. Becvar (ed.), Handbook of family resilience (pp. 321-337). New York: Springer Science + Business Media. doi: 10.1007/ 978-1-4614-3917-2_19

Greeff, A. P. \& Ritman, I. N. (2005). Individual Characteristics Associated With Resilience in Single-Parent Families [Abstract]. Psychological Reports, 96, 36-42. doi: 10.2466/PR0.96.1.36-42

Hartshorne, T. S., Schafer, A., Stratton, K. K., \& Nacarato, T. M. (2013). Family resilience relative to children with severe disabilities. In D. S. Becvar (ed.), Handbook of family resilience (pp. 361-383). New York: Springer Science + Business Media. doi: 10.1007/978-1-4614-3917-2_21

Hawley, D. R. \& DeHaan, L. (1996). Toward a definition of family resilience: Integrating life-span and family perspectives. Family Process, 35, 283-298. doi: 10.1111/j.1545-5300.1996.00283.x

Kaya, M. \& Arici, N. (2012). Turkish Version of Shortened Family Resiliency Scale (FRAS): The Study of Validity and Reliability. Procedia - Social and Behavioral Sciences, 55, 512-550. doi: 10.1016/j.sbspro.2012.09.531

Lachowska, B. (2012). Praca i rodzina - konflikt czy synergia? [Work and family - conflict or synergy?]. Lublin: Wydawnictwo KUL.

Lachowska, B. (2014). Pozytywna psychologia rodziny w teorii i praktyce [Positive psychology of the family - in theory and practice]. In I. Janicka \& H. Liberska (eds.), Psychologia rodziny [Psychology of the family] (pp. 535-565). Warsaw: Wydawnictwo Naukowe PWN.

Lavee, Y., Olson, D., \& McCubbin, H. (1987). The effect of stressful life events and transitions on family functioning and well-being. Journal of Marriage and the Family, 49, 857-873.

Li, Y., Zhao, Y., Zhang, J., Lou, F., \& Cao, F. (2016). Psychometric properties of the shortened Chi- 
nese version of the Family Resilience Assessment Scale. Journal of Child and Family Studies, 1-8. doi: 10.1007/s10826-016-0432-7

McCubbin, H., \& McCubbin, M. (1988). Typologies of resilient families: emerging roles of social class and ethnicity. Family Relations, 37, 247-254.

McCubbin, H. I., Thompson, A. I., \& McCubbin, M. A. (1996). Family assessment: Resiliency, coping and adaptation : inventories for research and practice. Madison: University of Wisconsin Publishers.

McCubbin, L. D. \& McCubbin, H. I. (2013). Resilience in ethnic family systems: A relational theory for research and practice. In D. S. Becvar (ed.), Handbook of family resilience (pp. 175-195). New York: Springer Science + Business Media. doi: 10.1007/978-1-4614-3917-2_11

Nichols, W. C. (2013). Roads to understanding family resilience: 1920 s to the twenty-first century. In D. S. Becvar (ed.), Handbook of family resilience (pp. 3-16). New York: Springer Science + Business Media. doi:10.1007/978-1-4614-3917-2_1

Openshaw, K. P. (2011). The Relationship Between Family Functioning, Family Resilience, and Quality of Life Among Vocational Rehabilitation Clients (Dissertation). Retrieved from http://digitalcommons. usu.edu/cgi/viewcontent.cgi? article $=2084 \&$ con text $=$ etd

Patterson, J. (2002). Integrating family resilience and family stress theory. Journal of Marriage and Family, 64, 349-360.

Plumb, J. A. (2011). The impact of social support and family resilience on parental stress in families with a child diagnosed with an autism spectrum disorder (Dissertation. Paper 14). Retrieved from http://repository.upenn.edu/edissertations_sp2/14/

Rahimian, E., Zadech Mohammadi, A., \& Pakdaman.S. (2015). Effectiveness of art therapy based on unity oriented approach on family resiliency of adolescent having unsuitable parenting. Trends in Life Sciences. An International Peer-Revieved Journal, 4, 400-403. Retrieved from http://www.sciencejournal.in/current-archives/trends-in-life-sciences/ volume-4-issue-4-2015-part-1/

Reker, G. T. (2005). Meaning in life of young, middle-aged, and older adults: Factorial validity, age, and gender invariance of the Personal Meaning Index (PMI). Personality and Individual Differences, 38, 71-85. doi: 10.1016/j.paid.2004.03.010

Ruszkiewicz, D. (2013). Narzeczeństwo w procesie tworzenia matżeństwa - empiryczny zarys proble$m u$ [Betrothal period in the process of marriage - empirical outline of the problem]. Piotrków Trybunalski: Naukowe Wydawnictwo Piotrkowskie przy Filii Uniwersytetu Jana Kochanowskiego.

Seo, S. J., \& Jung, M. S. (2013). Effect of Family Flexibility on the Idea of Adolescents Suicide-The Senior Year of High school Boys. The Journal of the Korea Contents Association, 13, 262-274. Retrieved from http://ocean.
kisti.re.kr/downfile/volume/kocon/CCTHCV/2013/ v13n5/CCTHCV_2013_v13n5_262.pdf

Simelane, A. (2015). The role of resilience and socio-economic status in the parenting of children with autism spectrum disorder in South Africa (Doctoral dissertation). Retrieved from http:// wiredspace.wits.ac.za/handle/10539/18281

Sixbey, M. T. (2005). Development of the family resilience assessment scale to identify family resilience constructs [Master's thesis]. Retrieved from https://education.ufl.edu/counselor-education/ dissertations-list/

Suk-Ja, Y. \& Hee-Jeong, K. (2013). The relations between Parent - Adolescent Communication and Family Resilience of University Students. The Journal of Digital Policy \& Management, 11, 23-40. Retrieved from http://ocean.kisti.re.kr/downfile/ volume/dpm/DJTJBT/2013/v11n8/DJTJBT_2013_ v11n8_23.pdf

Teixeira, A. V. B. (2015). Resiliência e stresse em pais de crianças com perturbações do espetro do autism (Master's thesis). Retrieved from https://sapientia.ualg.pt/handle/10400.1/7736

Van Breda, A. D. (2001). Resilience review: A literature review. Pretoria: South African Mental Health Service. Retrieved August 9, 2010, from http://www. adrian.vanbreda.org/

Walsh, F. (1996). The concept of family resilience: Crisis and challenge. Family Process, 35, 261-281.

Walsh, F. (2002). A family resilience framework: Innovative practice applications. Family Relations: An Interdisciplinary Journal of Applied Family Studies, 51, 130-137. doi:10.1111/j.1741-3729.2002.00130.x

Walsh, F. (2003). Family resilience: A framework for clinical practice. Family Process, 42, 1-18. doi: 10.1111/ j.1545-5300.2003.00001.x

Walsh, F. (2006). Strengthening Family Resilience ( $2^{\text {nd }}$ ed.). New York: Guilford Press.

Walsh, F. (2010). Spiritual diversity: Multifaith perspectives in family therapy. Family Process, 49, 330-348. doi: 10.1111/j.1545-5300.2010.01326.x

Walsh, F. (2012). Facilitating family resilience: Relational resources for positive youth development in conditions of adversity. In M. Ungar (ed.), The social ecology of resilience: $A$ handbook of theory and practice (pp. 173-185). New York: Springer Science + Business Media. doi: 10.1007/978-1-4614-0586-3_15

Walsh, F. (2013). Community-based practice applications of a family resilience framework. In D. S. Becvar (ed.), Handbook of family resilience (pp. 65-82). New York: Springer Science + Business Media. doi: 10.1007/978-1-4614-3917-2 5

Walsh, F. (2016). Family resilience: A developmental systems framework. European Journal of Developmental Psychology, 13, 313-324. doi:10.1080/17405 629.2016.1154035 